\title{
Ground support design under highly stressed conditions
}

\author{
A. Vakili AMC Consultants Pty Ltd, Australia \\ M.P. Sandy AMC Consultants Pty Ltd, Australia \\ M. Mathews Cobar Management Pty Ltd, Australia \\ B. Rodda Cobar Management Pty Ltd, Australia
}

\begin{abstract}
Development advance rates in mining projects have been increasing substantially in recent years and the number of mines operating at greater depth in Australia and other countries is increasing. In general, this requires more systematic ground support design in more severe ground conditions such as those that exist in highly stressed and highly anisotropic rock masses.

In particular, more attention is required in relation to the timing of ground support installation and the interaction between the ground support and the rock mass.

This paper describes a numerical modelling method that can be used as a tool to optimise the ground support design in more severe ground conditions. A new quantitative guideline is presented, summarising the typical response of 'massive', 'moderately jointed' and 'highly jointed' rock masses to increasing stress levels. A case study is also presented, in which advanced modelling techniques were used to improve the ground support performance through optimisation of timing and stiffness of the ground support system at the CSA mine in Cobar, New South Wales. The ground displacement and closure strain were carefully monitored at CSA, and a comprehensive development and stope damage database was compiled. The numerical model was then accurately calibrated using the instrumentation data and the damage history of the mine.
\end{abstract}

\section{Introduction}

Understanding the transition from 'low-stress' to 'high-stress' conditions is a key factor for an effective ground support design in underground mines as they progress to greater depths (Sandy et al., 2010).

Depending on the characteristics of the rock mass, squeezing or strain burst problems can cause difficulties in high-stress conditions. This can lead to increased support costs, delays associated with rehabilitation, and disruption to production. Ultimately, in more severe cases, it may result in complete drive closure and the introduction of 'exclusion' zones or periods to manage exposure to seismic hazards.

The actual depth at which the stress-related problems are expected is a function of the local pre-mining stress field, rock strength, joint properties, and mining-induced stresses.

Many attempts have been made in the past to quantify the onset of stress-related damage for various ground conditions. In 2001, Hoek proposed a relationship between the closure strain (radial boundary displacement/opening radius) and the ratio of rock mass strength over pre-mining stress that could be used to predict squeezing problems. This relationship was developed based on the results of parametric finite element modelling and suggests that stress-related problems initiate when the closure strain exceeds $1 \%$. Others, such as Aydan et al. (1993), Singh et al. (2007), and Sakuri (1997), also proposed the critical strain limits at which squeezing damage can occur. Singh et al. (1992) suggested an empirical relationship which relates the $Q$ value to the depth at which squeezing problems can initiate (adopted from Potvin and Hadjigeorgiou, 2008).

The above methods mainly considered the rock mass as a continuum material, where rock mass continuum properties are downgraded from intact properties. However, as also demonstrated by Martin et al. (1999), 
the majority of stress-related issues in underground mines are a function of both brittle failures of intact rock as well as interaction between the blocks that are generated due to the existence of discontinuities in the rock mass. Block size is an important factor that can directly influence the rock mass dilation and consequently affect the induced boundary strain and depth of failure.

Considering the above, it would seem that to accurately predict the induced strain and depth of failure in a blocky system, a continuum model is not suitable. Instead, a discontinuum representation of the rock mass is required to accurately understand the failure mechanisms involved.

Sandy et al. (2010) proposed a stress-related damage classification scheme based on the estimates of depth and extent of excavation damage. Since closure strain varies with rock type, the depth of damage in this classification is considered a key parameter required for calculation of both reinforcement length and support pressures.

Using the results of monitoring data and numerical back analysis from a number of different mines, Vakili et al. (2012) related the closure strain to the damage levels proposed by Sandy et al. (2010). In their study, they proposed limiting strain values, which were dependent on how blocky the rock mass is, based on its GSI value. The strain value for each damage level was mainly assigned based on engineering judgements.

More recent underground observations by the authors indicate that in some cases, significantly higher closure strain values than those recommended by Vakili et al. (2012) can take place before any extreme stability issues are encountered. Hoek (2001) also reported a number of tunnels with strains as high as $4 \%$, which had no major stability problems.

As a result, a more systematic analytical approach is required to better understand the relationship of excavation closure versus severity and depth of induced damage in underground excavations.

In this paper, an advanced numerical modelling technique is introduced, which can accurately model the failure mechanism in brittle rock mass conditions as well as in more plastic (ductile) rock mass conditions.

Using this modelling technique, the depths of damage and boundary displacements were accurately reproduced for two historical cases. The calibrated numerical model was then used to construct a number of different rock mass conditions, from massive to highly fractured, to study the failure mechanism, depth of damage, and closure strain values for each condition.

A new guideline is proposed for estimation of closure strain and depth of damage based on magnitude of in situ stress, uniaxial strength of intact rock, and blockiness of the rock mass. Also, a modified version of the Sandy et al. (2010) damage classification scheme is presented, which incorporates the results of this study.

Isotropic rock mass conditions were assumed for all the constructed models in this study. Anisotropic rock mass conditions, e.g. highly foliated/bedded conditions, can exhibit significantly different behaviour under high-stress levels. This is explained in more detail by Sandy et al. (2010).

For that reason, the guidelines presented in this paper should only be used for isotropic rock mass conditions. Work is currently underway by the authors to develop similar guidelines for anisotropic rock mass conditions.

A case study is also presented in this paper in which advanced numerical modelling techniques were used together with carefully monitored ground displacements to improve the ground support system at the CSA mine.

\section{$2 \quad$ Modelling rock mass response to increasing stress levels}

One of the key factors in modelling the rock mass response to increasing stress levels is the capability of the modelling software to accurately model the failure mechanism through simulation of brittle intact rock damage as well as the damage induced due to existence of discontinuities, e.g. joints.

Traditionally, only hybrid numerical codes, which combine the benefits of finite element methods and discrete element methods, could model the complex failure mechanism described above. 
The authors developed an improved modelling approach, which combines the use of advanced meshing programs, such as Sandia's mesh generation code CUBIT, to construct discontinuum models using Itasca's discrete element code 3DEC. In addition, a contact stiffness reduction algorithm was developed for these models to more accurately model the brittle intact rock failure.

This method can accurately model the complex failure mechanisms observed in higher stress underground conditions as shown in Figure 1.
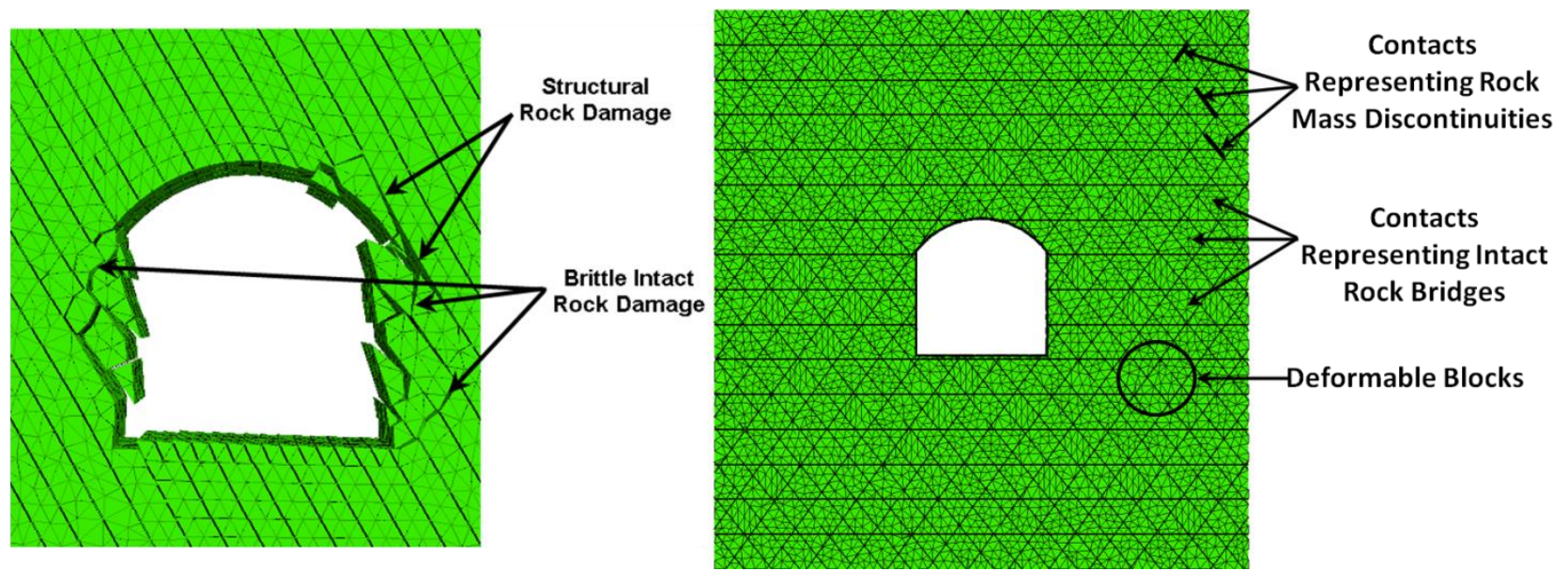

\section{Figure 1 Improved 3DEC modelling approach for analysis of rock response at high-stress conditions}

In order to validate this modelling technique and calibrate a base model for this study, the authors used the information from two case histories, where stress-induced damage was reported.

The first case history was based on an experiment by Atomic Energy of Canada Limited, which involved the excavation of a 3.5 m diameter circular test tunnel in massive granite (Read, 1994).

Information provided by Hajiabdolmajid et al. (2002) about this experiment was used to calibrate a 3DEC model, which can reproduce similar stress-induced damage to those observed on-site. The calibrated 3DEC micro-properties are in the same order of magnitude as reported by Kazerani and Zhao (2010), who studied the impact of micromechanical properties on macro-properties through UDEC simulation of triaxial laboratory testing on Augig granite. Detailed explanation of input parameters used for the numerical models in this study is outside the scope of this paper. However, those details will be presented in future publications.

Figure 2 shows the shape of the failed zone observed around the circular test tunnel as well as the model prediction of the failed zone using the improved 3DEC modelling approach. 

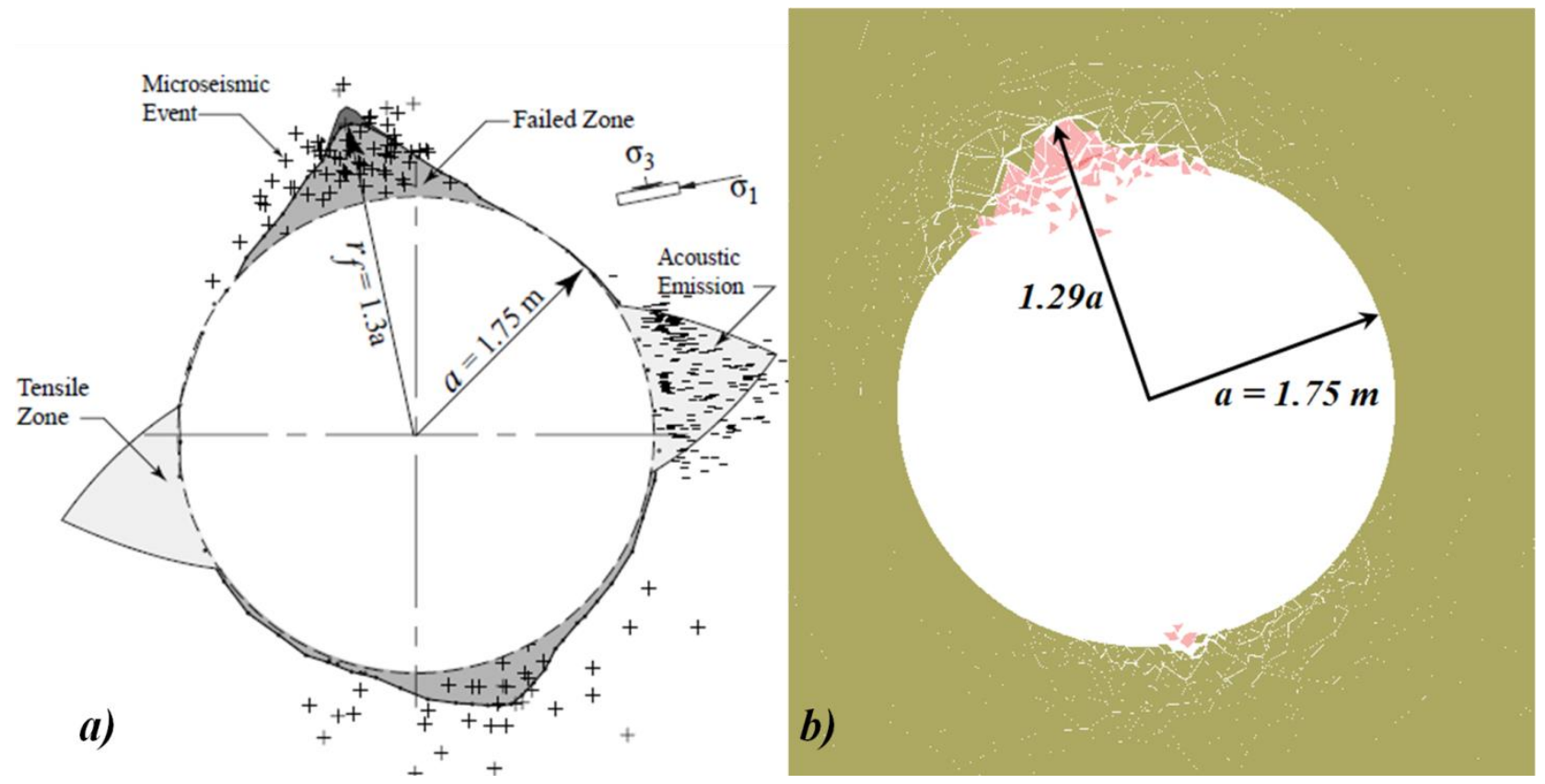

Figure 2 a) Shape of the failed zone observed around the circular test tunnel as reported by Hajiabdolmajid et al. (2002); b) Model prediction of the failed zone using improved 3DEC modelling technique

The second case history was based on observations of stress-induced buckling in a ventilation shaft at CSA mine. The subject shaft was excavated by raise boring at a depth of approximately 1,400 $\mathrm{m}$ below surface ( $5 \mathrm{~m}$ diameter). Shortly after excavation, severe time-dependant buckling failure was observed due to the existence of closely spaced foliation defects.

As shown in Figure 3, a calibrated 3DEC model has been able to reproduce the observed buckling failure mechanism and to accurately predict the correct depth of failure and boundary displacements.

\section{Observed Buckling Mechanism}

Interpreted buckling mechanism

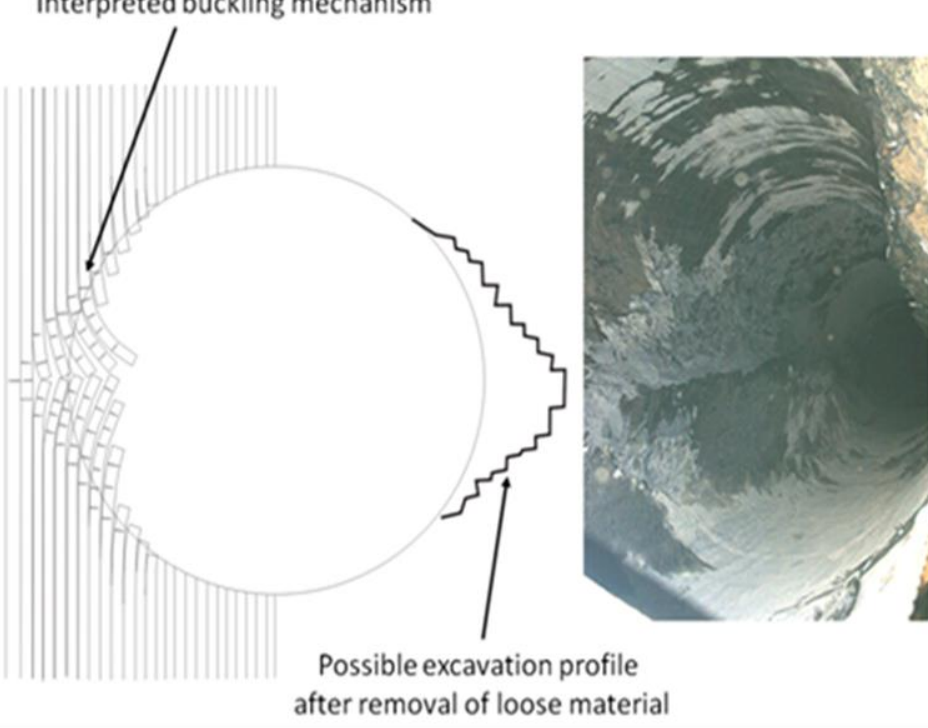

Modelled Buckling Mechanism in 3DEC

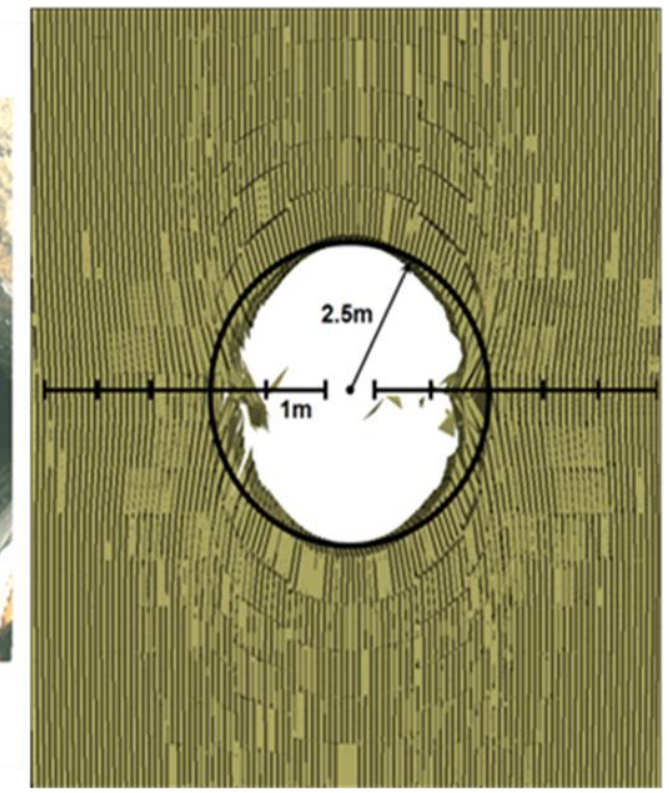

Figure 3 a) Observed buckling mechanism around a ventilation shaft at CSA mine; b) Model prediction of the buckling mechanism using improved ${ }_{3} \mathrm{DEC}$ modelling technique 
The above validation studies confirmed that the adopted modelling method is suitable for accurately predicting the extent of failure and boundary displacements in both brittle and plastic (ductile) rock mass conditions.

\section{$3 \quad$ Numerical assessment of typical rock mass responses to increasing stress levels}

Using the calibrated input parameters adopted for massive granite, the authors constructed a base numerical model to study the impact of stress and block size on depth of damage and closure strain. For this purpose, nine different models were constructed using different block sizes (different spacing of intersecting joints) and different ratios of the pre-mining major principal stress $\left(\sigma_{1}\right)$ to the uniaxial compressive strength of the intact rock $\left(\sigma_{c}\right)$.

A typical $5 \times 5 \mathrm{~m}$ underground drive profile was used in the model, and average joint properties as recommended by Barton (1974) were adopted for joint contacts in 3DEC.

In order to correctly measure the boundary displacements in these models, a very thin $(<50 \mathrm{~mm})$ and soft elastic liner was installed within the internal boundary of each excavation to stop excessive displacements due to block detachments from the excavation boundaries. However, a very small elastic modulus was assigned to this liner to avoid any reinforcement action and to measure more accurate displacements. This liner is also equivalent to a minimum surface support, e.g. mesh, that is commonly used in most underground mines, as standard support, to control scats.

For each model, the average boundary displacement was carefully monitored, as well as the depth of brittle rock damage $\left(d_{f}\right)$. A summary of results is shown in Figure 4, where results are plotted against a matrix proposed by Martin et al. (1999).

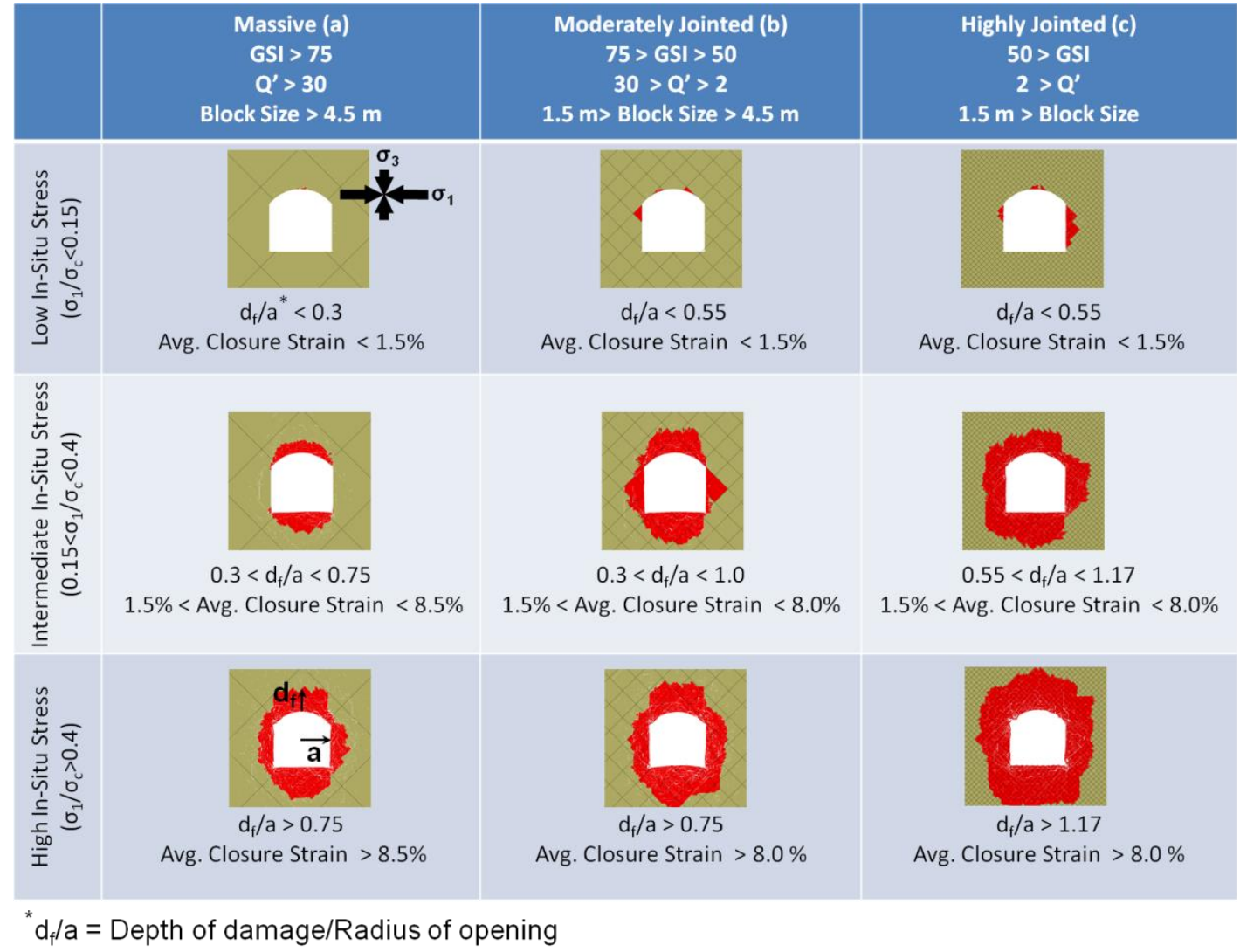

Figure 4 Tunnel instability and brittle failure as a function of rock blockiness and the ratio of maximum far-field stress to the uniaxial compressive strength in isotropic rock mass condition (modified from Martin et al., 1999) 
It should be noted that the block size values were correlated with $Q^{\prime}$ values based on the results of a case study conducted by Maerz and Geramin (1996). In addition, GSI values were estimated using the recommended empirical relationships, i.e. $G S I=9 \operatorname{Ln}\left(Q^{\prime}\right)+44$.

The results suggest that the blockiness of the rock mass has very little impact on induced boundary strain, and that in turn, the drive closure is mainly controlled by the ratio of $\sigma_{1}$ over $\sigma_{\mathrm{c}}$. This can be explained by the fact that, although in a blockier rock mass there is more degree of freedom for blocks to move and deform, there is also a higher potential for rock mass dilation due to the rotation of larger slabs and blocks near the excavation boundary in a massive rock mass. It appears that these two effects to some degree cancel each other, and therefore similar boundary displacements are expected in similar in situ stress conditions, regardless of rock mass blockiness.

However, as shown in Figure 4 , the depth of damage $\left(d_{f}\right)$ can be impacted largely by both in situ stress and rock mass blockiness. The results imply that even though in massive rock masses, similar boundary displacements are expected under similar stress conditions. However, the depth of damage is expected to be smaller. Therefore, these ground conditions can be more easily managed than those in similar in situ stress conditions, but in a blockier rock mass. This is mainly because of the impact of higher dilation in more massive rock masses, where the dilation effect increases the confinement levels close to the boundary of the excavation.

Figures 5 and 6 show the relationships, resulting from this modelling study, between depth of failure, stress levels, block size, closure strain, and expected damage levels.

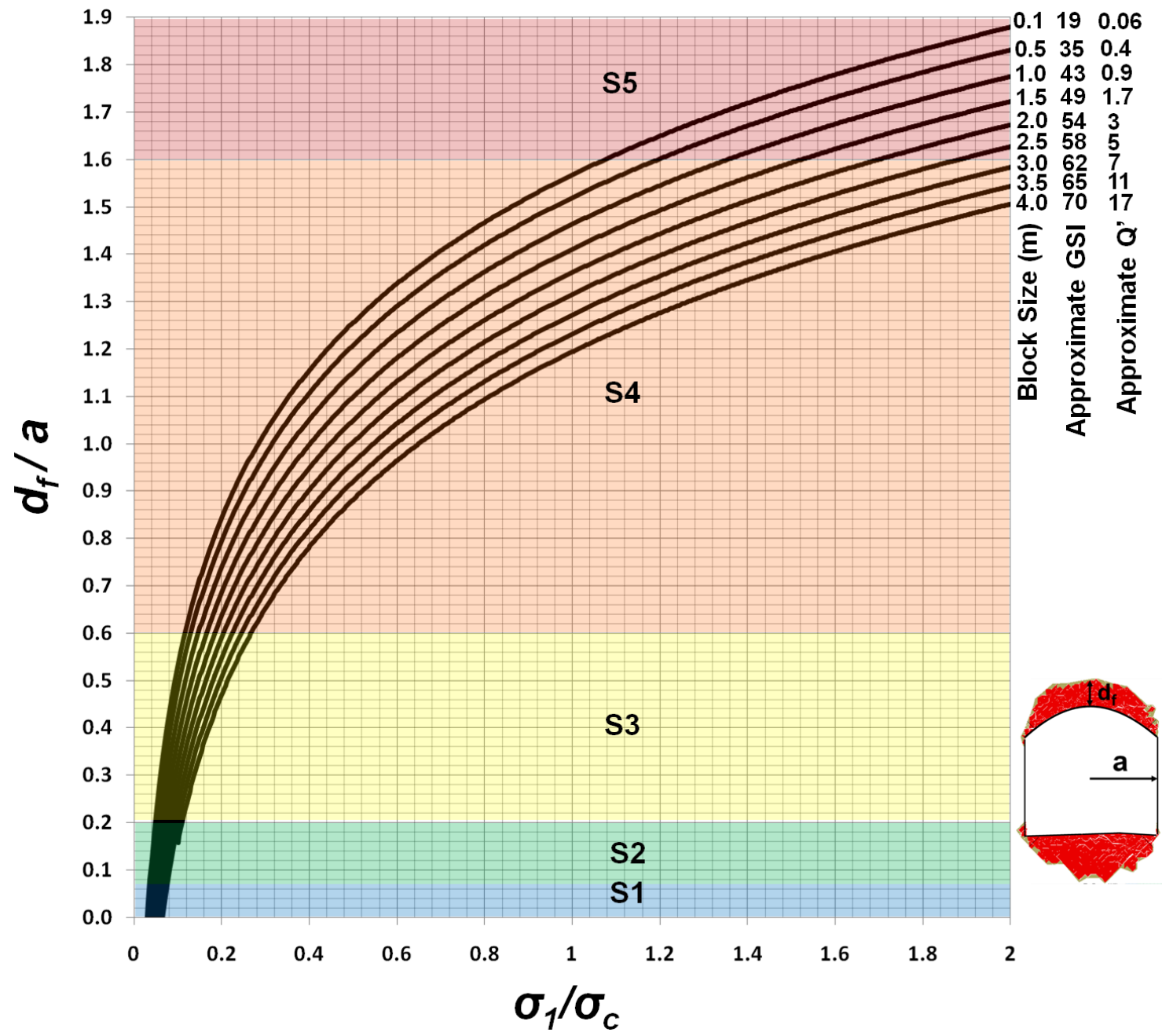

Figure 5 Relationship between depth of failure, block size and stress levels in isotropic rock mass condition 


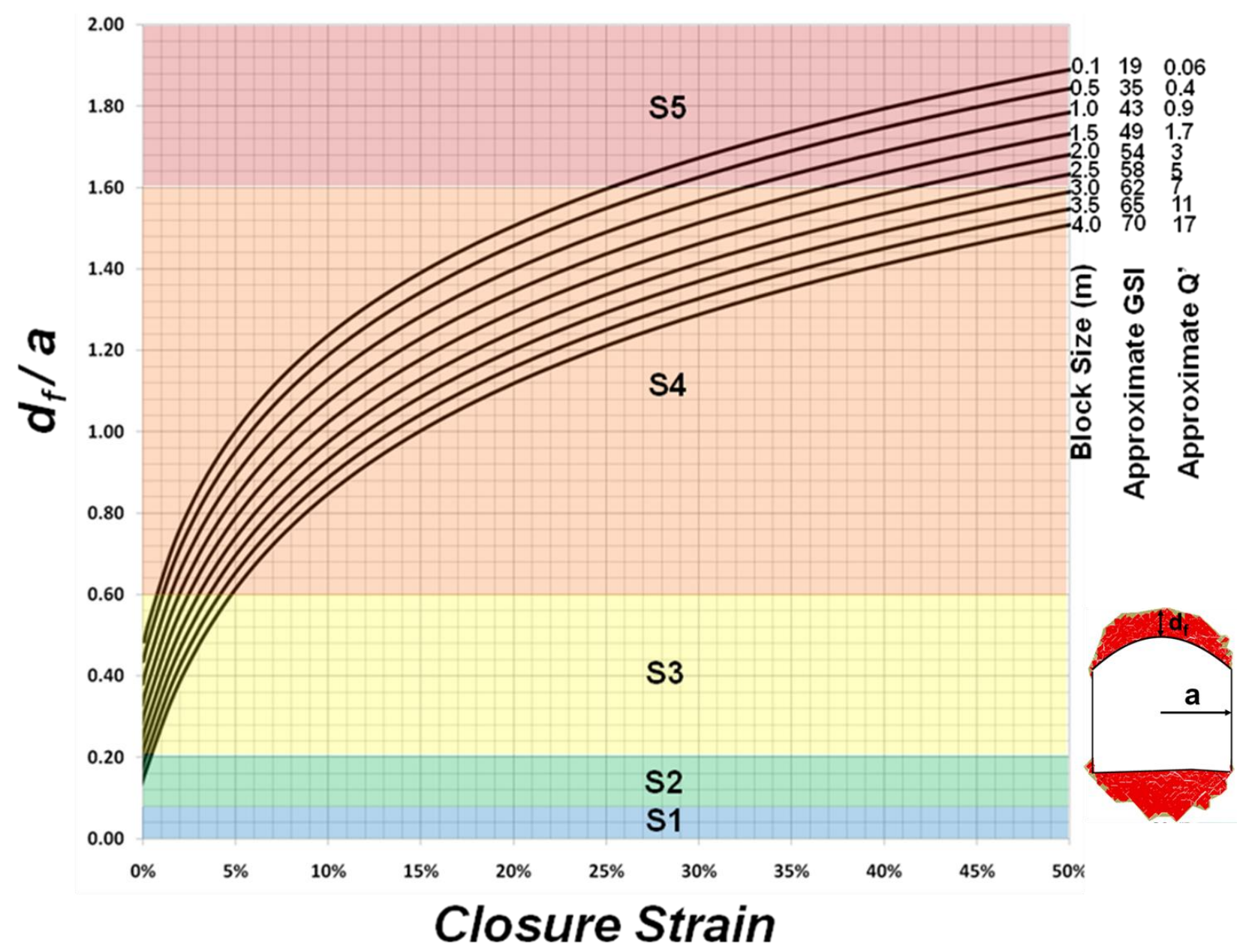

Figure 6 Relationship between depth of failure, block size and closure strain in isotropic rock mass condition

The results of the study were used to define a modified damage classification scheme based on the empirical estimates of depth of excavation damage proposed by Sandy et al. (2010). This scheme is shown in Table 1 and Figure 7.

The majority of severe squeezing and stress-related problems should be expected within the 'S4' damage level. Given the wide range of variations for ' $d_{f} / a^{\prime}$ ' and 'closure strains' within ' $S 4$ ' damage level, it may be advisable to further subdivide the squeezing and stress-related damage levels within ' $S 4$ ' damage level in the future. 
Table 1 Quantitative damage classification scheme for isotropic rock mass condition (modified from Sandy et al., 2010)

\begin{tabular}{|c|c|c|c|c|c|c|c|c|}
\hline \multirow{2}{*}{$\begin{array}{c}\text { Damage } \\
\text { Level }\end{array}$} & \multirow{2}{*}{$\begin{array}{c}\text { General } \\
\text { Description }\end{array}$} & \multirow[t]{2}{*}{ Expected Rock Mass Behaviour } & \multirow[t]{2}{*}{ Expected Support Requirement } & \multirow{2}{*}{$\begin{array}{l}\text { Potential } \\
\text { Rehabilitation } \\
\text { Requirement }\end{array}$} & \multirow{2}{*}{$\frac{d_{f}}{a}$} & \multicolumn{3}{|c|}{ Approximate Closure Strain } \\
\hline & & & & & & $\mathbf{I}^{*}$ & II & III \\
\hline So & $\begin{array}{l}\text { No visible } \\
\text { damage }\end{array}$ & No spalling, slabbing or failure. & None or surface support only. & None & 0 & $<1.0 \%$ & $<0.7 \%$ & $<0.2 \%$ \\
\hline S1 & $\begin{array}{c}\text { Minor } \\
\text { damage }\end{array}$ & $\begin{array}{l}\text { Potential for small wedges or blocks (with edge } \\
\text { length of approximately less than } 20 \mathrm{~cm} \text { ) to fall or } \\
\text { slide. }\end{array}$ & $\begin{array}{l}\text { Prevention of progressive unravelling and fall of } \\
\text { wedges/blocks, e.g. friction bolts and surface support (mesh } \\
\text { or less than } 25 \mathrm{~mm} \text { shotcrete). }\end{array}$ & None & $0-0.08$ & & & \\
\hline S2 & $\begin{array}{l}\text { Moderate } \\
\text { damage }\end{array}$ & $\begin{array}{l}\text { Potential for intermediate wedges or blocks (with } \\
\text { edge length approximately between } 20-50 \mathrm{~cm} \text { ) to } \\
\text { fall or slide. }\end{array}$ & $\begin{array}{l}\text { Prevention of progressive unravelling and fall of } \\
\text { wedges/blocks, e.g. systematic rockbolting or cable bolting } \\
\text { and surface support ( } 25 \text { to } 75 \mathrm{~mm} \text { fibrecrete). }\end{array}$ & Minor & $0.08-0.2$ & & & \\
\hline S3 & $\begin{array}{l}\text { Significant } \\
\text { damage }\end{array}$ & $\begin{array}{l}\text { - Potential for large wedges or blocks (with } \\
\text { edge length approximately greater than } \\
50 \mathrm{~cm} \text { ) to fall or slide. } \\
\text { - Surface slabbing, spalling and possible mild } \\
\text { rockburst damage in massive rock mass. } \\
\text { - } \quad \text { Possible minor squeezing in blocky rock mass. } \\
\text { excavation surfaces. 'Bagging' in the mesh } \\
\text { clearly developed. Isolated friction bolt head } \\
\text { failures. }\end{array}$ & $\begin{array}{l}\text { Retention of broken rock and control of rock mass dilation } \\
\text { or squeezing, e.g. systematic rockbolting or cable bolting } \\
\text { and surface support ( } 75 \text { to } 100 \mathrm{~mm} \text { fibrecrete). }\end{array}$ & Moderate & $0.2-0.6$ & $\begin{array}{l}1.0- \\
6.0 \%\end{array}$ & $\begin{array}{l}0.7- \\
2.5 \%\end{array}$ & $\begin{array}{l}0.2- \\
2.0 \%\end{array}$ \\
\hline S4 & $\begin{array}{c}\text { Severe } \\
\text { damage }\end{array}$ & $\begin{array}{l}\text { - Mild to heavy squeezing problems in blocky } \\
\text { rock mass. } \\
\text { - Heavy surface slabbing and/or heavy } \\
\text { rockburst damage in massive rock mass. } \\
\text { In supported ground, many bolts broken in } \\
\text { shear, mesh severely bagged, some local } \\
\text { rockfalls. }\end{array}$ & $\begin{array}{l}\text { Retention of broken rock and control of rock mass dilation } \\
\text { or squeezing. } \\
\text { Great care should be given to support installation time and } \\
\text { relative distance from the face. } \\
\text { De-bonded bolts and/or dynamic support might be required } \\
\text { to accommodate large deformation, excessive depth of } \\
\text { damage or dynamic loading, e.g. systematic rockbolting or } \\
\text { cable bolting and surface support (greater than } 100 \mathrm{~mm} \\
\text { fibrecrete and steel set in heavily squeezing condition). }\end{array}$ & Significant & $0.6-1.6$ & $\begin{array}{c}6.0- \\
70.0 \%\end{array}$ & $\begin{array}{c}2.5- \\
40.0 \%\end{array}$ & $\begin{array}{c}2.0- \\
25.0 \%\end{array}$ \\
\hline S5 & $\begin{array}{l}\text { Extreme } \\
\text { damage }\end{array}$ & $\begin{array}{l}\text { - Extreme squeezing problems in blocky rock } \\
\text { mass. } \\
\text { - } \quad \text { Extreme rockbursting in massive rock mass. } \\
\text { nearly complete drive closure. }\end{array}$ & Not applicable. & $\begin{array}{l}\text { Access not } \\
\text { advisable, } \\
\text { beyond } \\
\text { rehabilitation }\end{array}$ & $>1.6$ & $>70.0 \%$ & $>40.0 \%$ & $>25.0 \%$ \\
\hline
\end{tabular}

*I = Massive rock mass; II = Moderately jointed rock mass; III = Heavily jointed rock mass. 


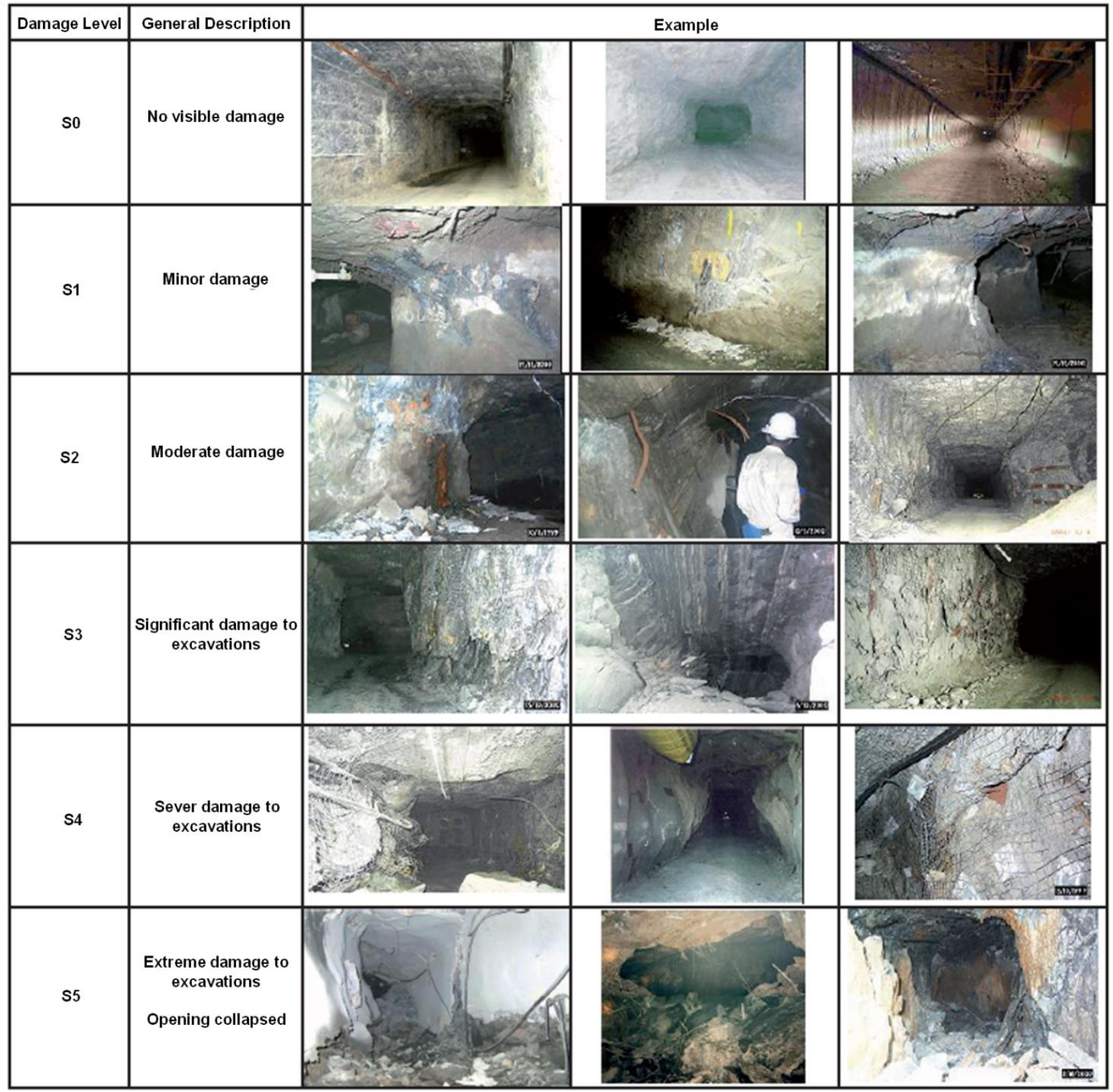

Figure 7 Examples of damage levels in the classification scheme proposed by Sandy et al. (2010)

The guidelines recommended above are only suitable for isotropic rock mass conditions, where the blocks within the rock mass have more or less similar edge lengths.

In anisotropic rocks, e.g. highly foliated/bedded rock mass, where rock blocks have irregular edge lengths and very high aspect ratios, response to higher stress conditions can significantly differ. This is further explained by Sandy et al. (2010).

A similar study is currently underway to develop similar guidelines for stress-induced damage in anisotropic rock mass conditions.

\section{$4 \quad$ Importance of timing of ground support installation under highly stressed conditions}

Time dependency is one of the main characteristics of stress-related damage in the ' $\mathrm{S} 4$ ' damage level. This is particularly important for ground support design. 
Overlain on this is the effect of progressive excavation steps; as the face is advanced, changes in the stress field including degree of confinement, can initiate new phases of deformation.

A conceptual plot is shown in Figure 8 , showing the greater importance of ground support installation timing, i.e. installation distance from excavation face, under highly-stressed conditions.

In lower-stress conditions, the maximum radial support pressure will rarely exceed the maximum available pressure from conventional support systems and therefore there is lower sensitivity to support installation distance from the face. The ground support systems under these conditions can be installed almost immediately after each face advance. This will help to minimise boundary displacement as much as possible.

Conversely, under highly stressed conditions, immediately after excavation of the face, the maximum radial pressure can quickly exceed the maximum available pressure from the conventional support systems. Therefore, secondary support installation should be delayed until further face advance, when the maximum radial pressure from ground reaches lower levels. On the other hand, too much delay in support installation can reduce the effectiveness of the support system because the majority of excavation radial displacement might have taken place before that stage.

As a result, a successful ground support design in high-stress conditions requires a good understanding of the interaction between the ground support and the rock mass to determine the best timing for support installation. This is not possible without careful monitoring, through instrumentation, of the depth of damage, displacement, and stress. In addition, numerical modelling is often required to validate and back analyse the monitoring results and to study different support systems.

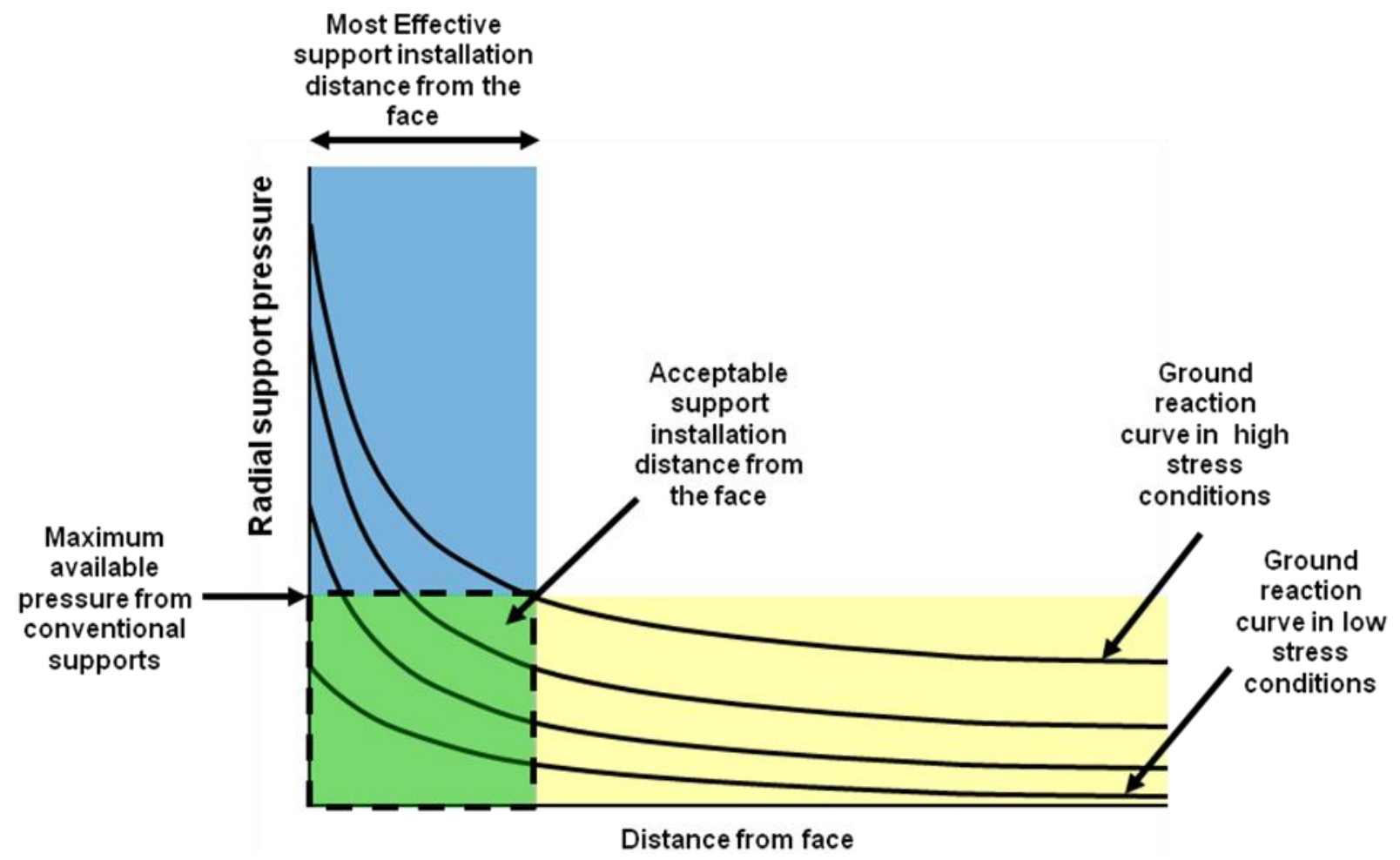

Figure 8 Conceptual ground reaction curves in high-stress versus low-stress conditions

\section{$5 \quad$ Case study - improved ground support design at CSA mine}

The CSA Mine is an underground operation located $9 \mathrm{~km}$ north of Cobar in central western New South Wales, Australia. The mine is currently operating at depths of around $1.5 \mathrm{~km}$ below the surface. The host rock at CSA comprises dominantly thin foliated siltstone. Lamination planes are subvertical $\left(80^{\circ}\right)$, dipping steeply west (Hosken et al., 2006). 
The host rock at CSA exhibits highly anisotropic behaviour and the laboratory uniaxial compressive strength of intact rock can vary by a factor of four, depending on loading direction relative to the foliation. This has led to buckling failure in drives and raises that are subparallel to foliation strike or dip.

Squeezing-related problems were encountered at several deep locations throughout the mine. As a result, a careful monitoring program was implemented by site personnel to better understand the interaction between the ground support and the rock mass. A number of extensometers and closure pins were installed in areas with high squeezing potential. Figure 9 shows a typical layout used for extensometer installation.

Closure strains of up to $8 \%$ were recorded for the sidewalls, which are subparallel to the foliation strike, and up to $0.8 \%$ strain was recorded for backs. The measured boundary displacements correlate well with the expected ground behaviour in anisotropic rock masses.

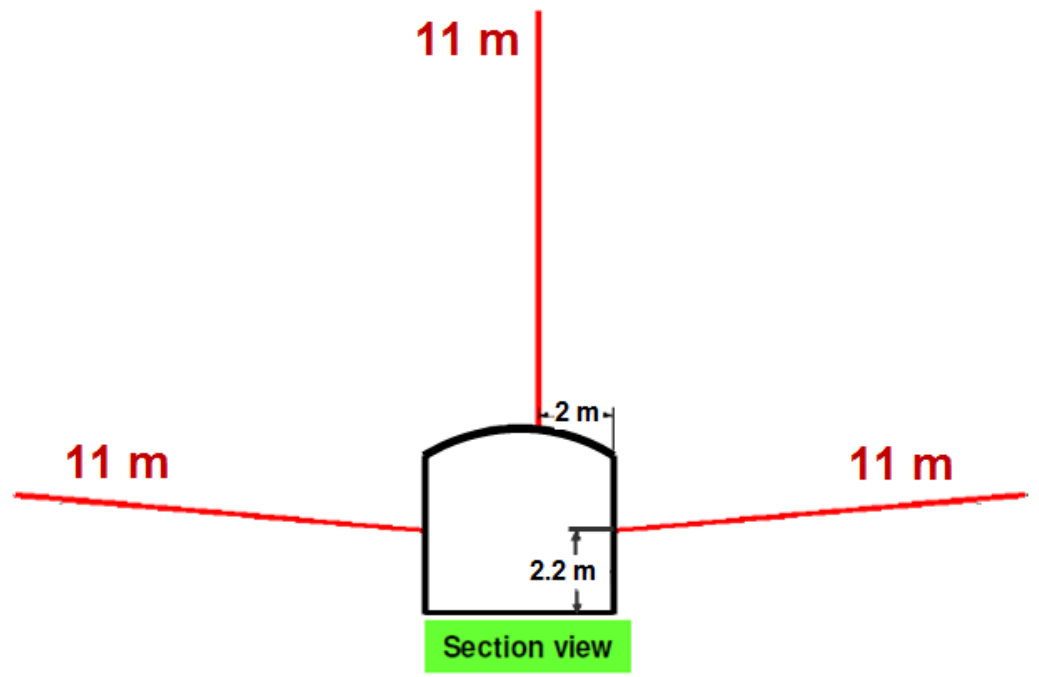

Figure 9 The layout used for extensometer installation at CSA mine

In addition, site personnel compiled a comprehensive development and stope damage database, which, together with the results of monitoring data, was used to calibrate numerical models.

For model calibration, stope overbreak, raisebore damage, historical development damage history, and displacement monitoring databases were used to fine-tune the input parameters for FLAC3D continuum modelling and 3DEC discontinuum modelling.

To evaluate and improve the old ground support system, a simple FLAC3D model was constructed as shown in Figure 10. The model comprised a 'liner' structural element to represent fibrecrete and a 'pile' structural element to represent cable bolt reaction. A number of face advances were simulated, and stress, load, and displacement were recorded both within the support system and within the modelled rock mass. 


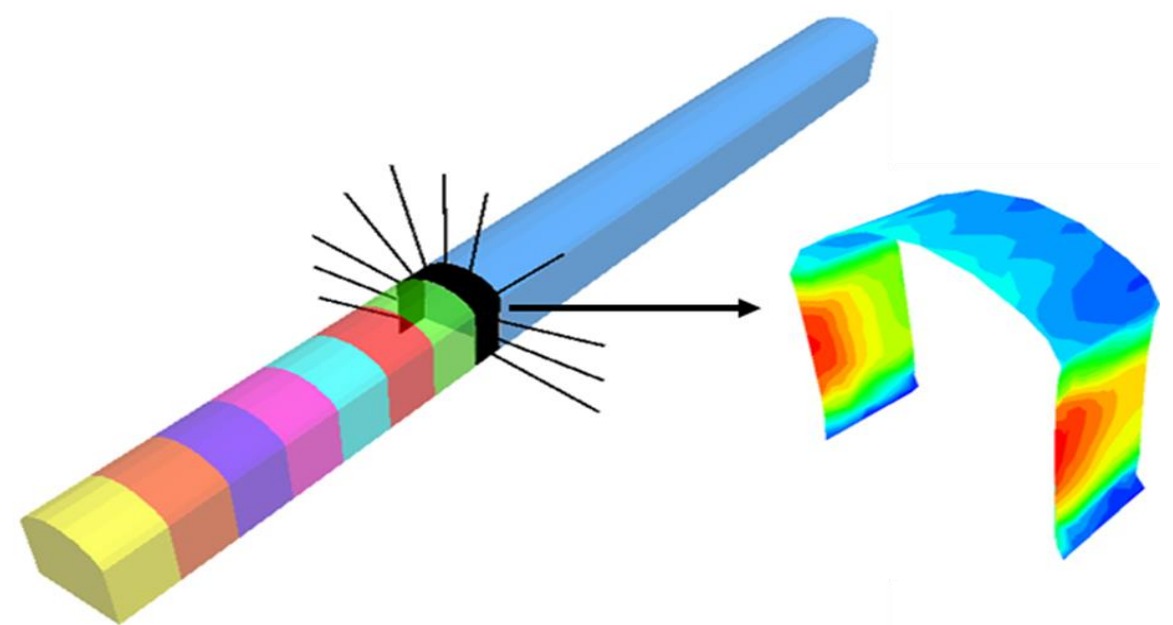

Figure 10 Simple $\mathrm{FLAC}_{3} \mathrm{D}$ model constructed for ground support design at CSA mine

The main purpose of this study was to optimise the secondary ground support system in place, comprising cable bolt and fibrecrete.

A ground reaction curve was determined for various depths and ground conditions. Figures 12 and 13 show example reaction curves for cable bolt and fibrecrete at a depth of approximately $1.4 \mathrm{~km}$ below surface.

The stiffness and maximum capacity of the cable bolts were determined onsite through pull testing. The stiffness and maximum radial capacity of fibrecrete was determined numerically through a sensitivity analysis varying thickness, Young's modulus and the UCS of liner element. The below equation resulted from the sensitivity analysis to calculate the maximum available pressure from the fibrecrete system.

Max. available pressure $(\mathrm{MPa})=0.027 \mathrm{UCS}+0.285 \mathrm{E}+17.7 \mathrm{~T}$

Where:

UCS $=$ the uniaxial compressive strength of fibrecrete (MPa).

$\mathrm{E}=\quad$ the Young's modulus of fibrecrete (GPa).

$\mathrm{T}=\quad$ the applied thickness of fibrecrete $(\mathrm{m})$.

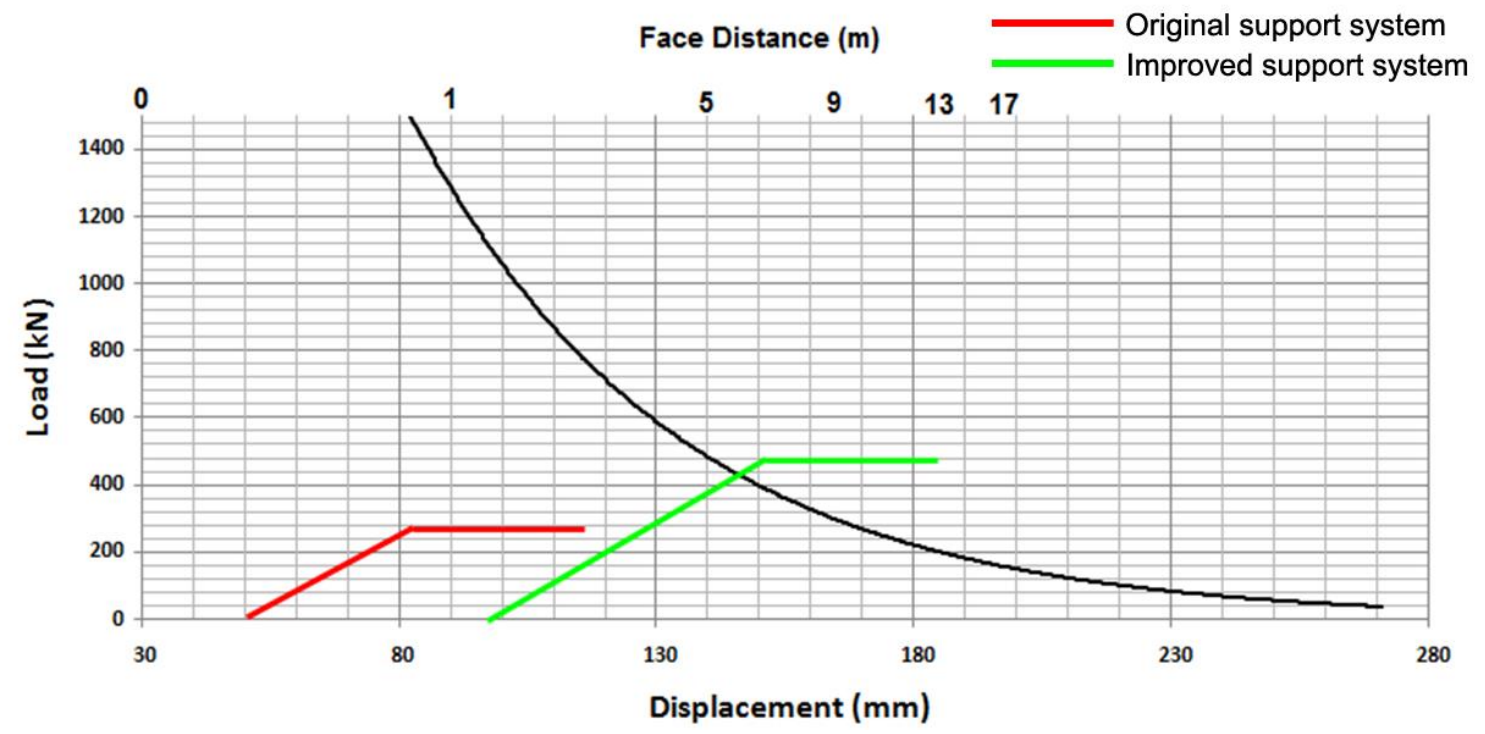

Figure 11 Ground reaction curve for cable bolt support system 


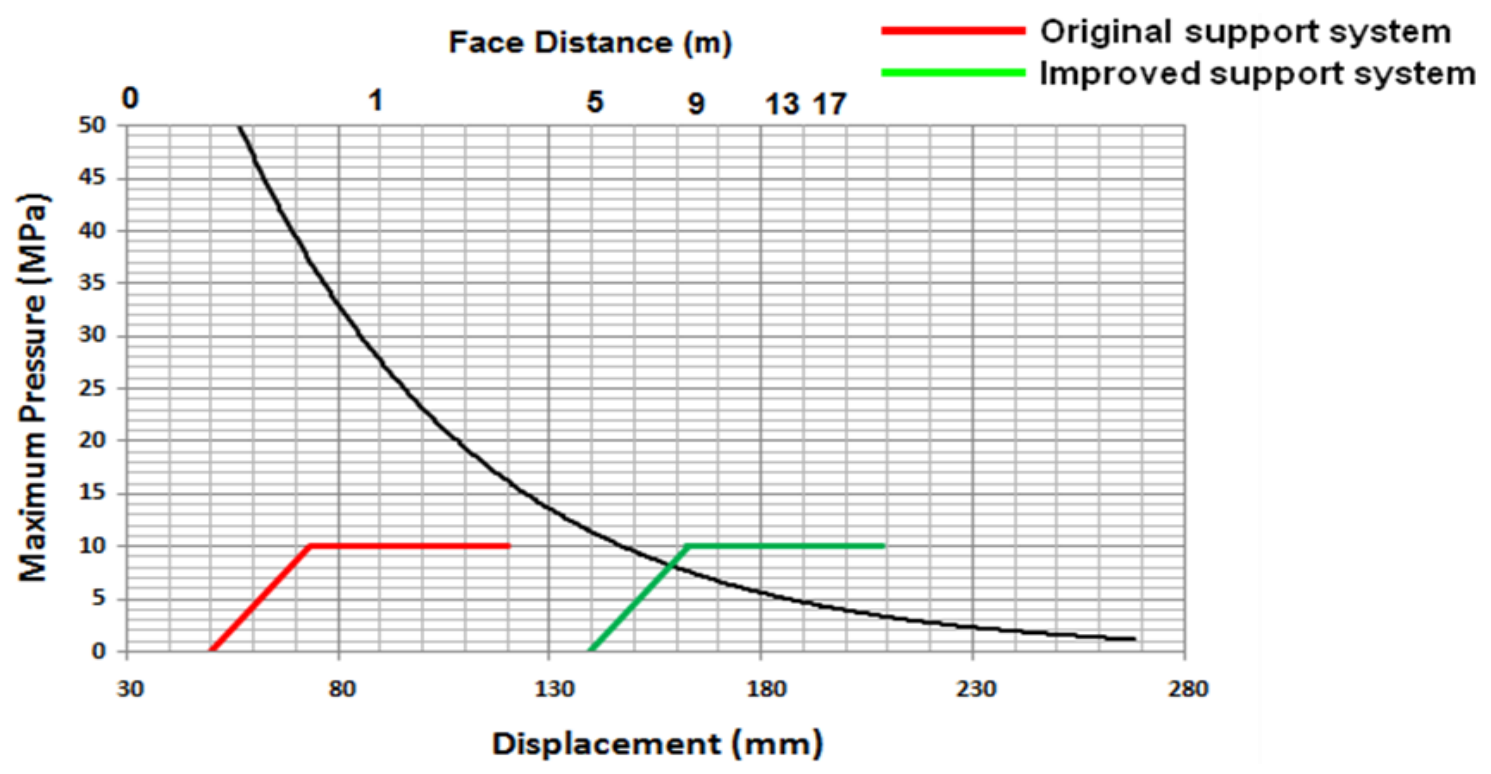

Figure 12 Ground reaction curve for fibrecrete support system

As shown in the above figures, previous secondary support systems were installed almost immediately after each face advance. Due to the fact that the radial pressure imposed by the ground exceeded the maximum available pressure from the support, premature cracking in fibrecrete and failure of cable bolts were inevitable. Consequently, it was decided to delay the secondary support installation for few more face advances and also to increase the cable bolt capacity using twin strand cables.

This new system was also implemented in the FLAC3D model to validate its suitability and effectiveness. As shown in Figure 13, the modelling results suggest substantial improvement in long-term effectiveness of the improved support system.

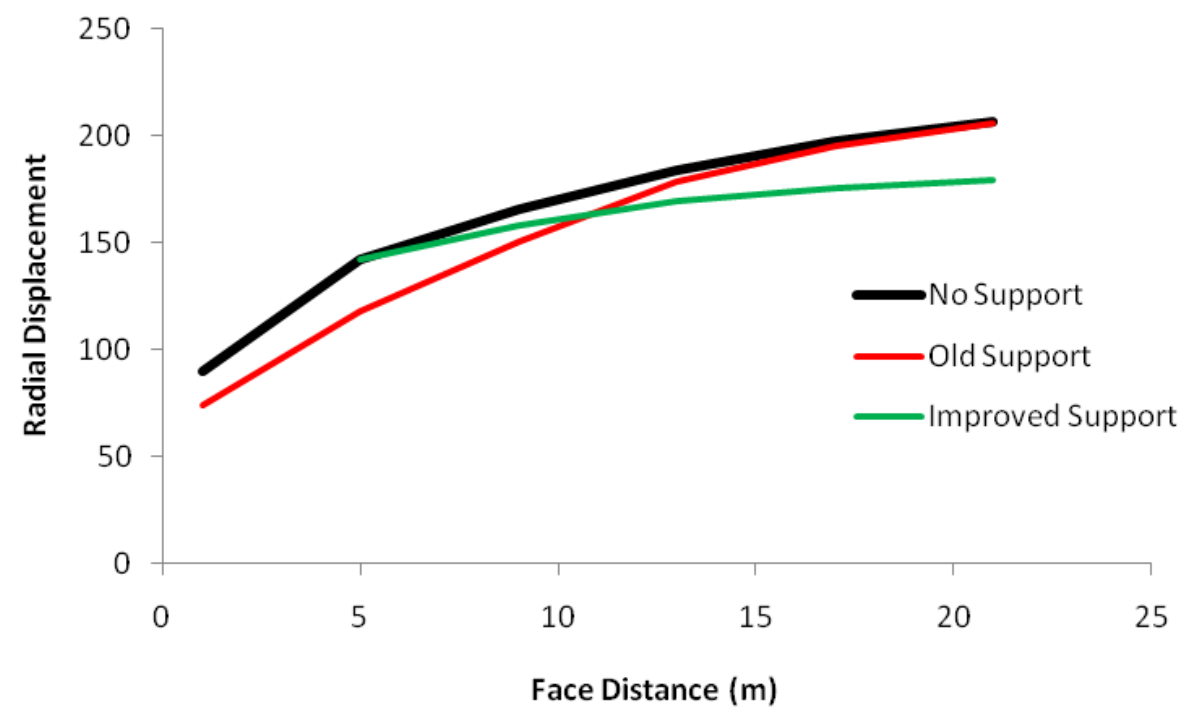

Figure 13 Numerical representation of effectiveness of the proposed improved support system

\section{Conclusions}

Numerical modelling together with careful underground monitoring can give very useful insights into the rock mass responses to increasing stress levels. A successful ground support design in high-stress conditions requires a good understanding of the interaction between the ground support and the rock mass to determine the best timing for support installation. 
This paper presents a new guideline, which summarises the typical response of 'massive', 'moderately jointed' and 'highly jointed' rock masses to increasing stress levels and the associated damage levels.

\section{References}

Aydan, O., Akagi, T. and Kawamoto, T. (1993) The squeezing potential of rock around tunnels: theory and prediction, Rock Mechanics and Rock Engineering, Vol. 2, pp. 137-163.

Barton, N. (1974) A review of the shear strength of filled discontinuities in rock, Norwegian Geotechnical Institute Publication, No. 105, Norwegian Geotechnical Institute, Oslo.

Hajiabdolmajid, V., Kaiser, P.K. and Martin, C.D. (2002) Modelling brittle failure of rock, International Journal of Rock Mechanics and Mining Sciences, Vol. 39(6), pp. 731-741.

Hoek, E. (2001) Big tunnels in bad rock, ASCE Journal of Geotechnical and Geoenvironmental Engineering, Vol. 127, No. 9, September 2001, pp. 726-740.

Hosken, J. Haren, E. and Winchester, A. (2006) Resource Modelling in an Evolving Mine - CSA Mine, Cobar, New South Wales, in Proceedings Sixth International Mining Geology Conference, 21-23 August 2006, Darwin, Australia, The Australasian Institue of Mining and Metallurgy, Carlton.

Kazerani, T. and Zhao, J. (2010) Micromechanical parameters in bonded particle method for modelling of brittle material failure, International Journal of Numerical and Analytical Methods in Geomechanics, Vol. 12, pp. 12-13.

Maerz, N.H. and Germain, P. (1996) Block size determination around underground openings using simulations, in Proceedings FRAGBLAST 5 Workshop on Measurement of Blast Fragmentation, J.A. Franklin and T. Katsabanis (eds), 23-24 August 1996, Montreal, Canada, pp. 215-223.

Martin, C.D., Kaiser, P.K. and McCreath, D.R. (1999) Hoek-Brown parameters for predicting the depth of brittle failure around tunnels, Canadian Geotechnical Journal, Vol. 36(1), pp. 136-151.

Potvin, Y. and Hadjigeorgiou, J. (2008) Ground support strategies to control large deformations in mining excavations, Journal of the Southern African Institute of Mining and Metallurgy, Vol. 108(7), pp. 397-404.

Read, R.S. (1994) Interpreting excavation-induced displacements around a tunnel in highly stressed granite, Ph.D. thesis, Department of Civil and Geological Engineering, University of Manitoba, Canada, $328 \mathrm{p}$.

Sakurai, S. (1997) Lessons learned from field measurements in tunnelling, Tunnelling and Underground Space Technology, Vol. 12(4), pp. 453-460.

Sandy, M., Sharrock, G., Albrecht, J. and Vakili, A. (2010) Managing the Transition from Low-stress to High-stress Conditions, in Proceedings Second Australasian Ground Control in Mining Conference, 23-24 November 2010, Sydney, Australia, The Australasian Institute of Mining and Metallurgy, Carlton.

Singh, B., Jethwa, J.L., Dube, A.K. and Singh, B. (1992) Correlation between observed support pressure and rock mass quality, Tunnelling and Underground Space Technology, Vol. 7, pp. 59-74.

Singh, M., Singh, B. and Choudhari, J. (2007) Critical strain and squeezing of rock mass in tunnels, Tunnelling and Underground Space Technology, Vol. 22, pp. 343-350.

Vakili, A. Sandy, M. and Albrecht, J. (2012) Interpretation of Non-linear Numerical Models in Geomechanics - a Case Study in the Application of Numerical Modelling for Raise Bored Shaft Design in a Highly Stressed and Foliated Rockmass, in Proceedings Sixth International Conference and Exhibition on Mass Mining (MassMin 2012), 10-14 June 2012, Sudbury, Canada. 